\title{
QUALIDADE SENSORIAL DA ALFACE CRESPA MINIMAMENTE PROCESSADA EMBALADA EM DIFERENTES FILMES PLÁSTICOS SOB ATMOSFERA MODIFICADA
}

\author{
Packaging evaluation to conditioning of minimally processed lettuce
}

Rosana Mendes Roversi ${ }^{1}$, Maria Lúcia Masson²

\begin{abstract}
RESUMO
A alface crespa minimamente processada foi acondicionada em cinco tipos de sacos plásticos confeccionados com diferentes filmes (PEBD-50, PEBD-60, PEBD-100, BOPP - PEBD e Conservax), sob atmosfera ativamente modificada com 5\% de $\mathrm{O}_{2}$ e $10 \%$ de $\mathrm{CO}_{2}$. Monitorou-se a atmosfera durante o armazenamento por meio da determinação das concentrações de $\mathrm{O}_{2}$ e $\mathrm{CO}_{2}$ no interior das embalagens. A determinação da vida útil baseou-se na avaliação da qualidade sensorial realizada por meio de Análise Descritiva Quantitativa - ADQ, aplicando-se escala hedônica de nove pontos para aparência e cinco pontos para sabor, aroma e textura. Determinaram-se as taxas de permeabilidade ao $\mathrm{O}_{2}$ e $\mathrm{CO}_{2}$ e a espessura dos filmes. Nos filmes com baixas taxas de permeabilidade (BOPP-PEBD e Conservax) ocorreu rápida degeneração dos tecidos celulares e perda da qualidade da alface. Os filmes com maiores taxas de permeabilidade (PEBD-50 e 60) propiciaram a rápida redução do $\mathrm{CO}_{2}$. Entretanto, todas as embalagens com atmosfera modificada proporcionaram os melhores resultados permitindo que a alface mantivesse características adequadas de consumo em até dez dias de armazenamento.
\end{abstract}

Termos para indexação: Conservação, atmosfera modificada, processamento mínimo, permeabilidade gasosa, vida útil, filmes flexíveis.

\begin{abstract}
The lettuce was packaged in five different plastic films in bags forms (LDPE-50, LDPE -60, LDPE -100, BOPP-LDPE and Conservax-trade mark), under active modified atmosphere of $5 \% \mathrm{O}_{2}$ and $10 \% \mathrm{CO}_{2}$. It was accompanied the atmosphere changes with the determination of the $\mathrm{O}_{2}$ and $\mathrm{CO}_{2}$ concentration inside the package during the storage. The shelf life was determined through sensorial evaluation whit Descriptive Quantitative Analyses using a nine points hedonic scale to visual quality and five points hedonic scale to taste, flavor, and texture. Permeability and thickness films characteristics were analyzed. In the films with lowers permeability rates (BOPP- LDPE and Conservax) it was favored quickly cellular tissues degeneration and lettuce quality loss. The films with higher permeability rates (LDPE -50 and LDPE -60) favored quickly $\mathrm{CO}_{2}$ reduction. In spite of this, all the modified atmosphere packaging obtained the best results allowing to lettuce keep the adequate consume characteristics until ten days under storage.
\end{abstract}

Index terms: Conservation, modified atmosphere, minimal process, gas permeability, shelf life, flexible films.

(Recebido para publicação em 20 de maio de 2004 e aprovado em 25 de maio de 2005)

\section{INTRODUÇÃO}

$\mathrm{O}$ aumento na demanda por produtos vegetais frescos e a procura por conveniência fez com que se desenvolvesse uma nova categoria de produtos no mercado: os vegetais minimamente processados (MP), que são produtos similares aos frescos, mas que passam por varias etapas de processamento como limpeza, classificação, pelagem e corte, que ocasionam mudanças fisiológicas nos tecidos. A taxa respiratória aumenta consideravelmente, ocorre maior exposição do conteúdo celular devido aos cortes promovendo um aumento da suscetibilidade à oxidação enzimática e à contaminação microbiológica. Devido a essas condições peculiares, a refrigeração se torna imprescindível no processamento e armazenamento desses produtos, pois esse processo diminui a velocidade das transformações bioquímicas das células e do desenvolvimento microbiológico (CHITARRA, 1998; KADER, 1986; NASCIMENTO et al., 2000; PINHEIRO, 2000; ROLLE \& CHISM, 1987; SHELFT, 1986; SHEWFELT, 1987; WILLEY, 1997).

A atmosfera modificada reduz a taxa respiratória e a produção de etileno dos tecidos e tem sido aplicada para prolongar a vida útil dos vegetais MP. Esse processo consiste em reduzir o nível de $\mathrm{O}_{2}$ e elevar o de $\mathrm{CO}_{2}$, respeitando-se os limites mínimos de $\mathrm{O}_{2}$ e máximos de $\mathrm{CO}_{2}$ de forma a evitar que ocorra a respiração anaeróbia ou alterações fisiológicas indesejáveis (manchas escuras e degradação dos tecidos). O metabolismo anaeróbio gera metabólitos indesejáveis como etanol, aldeídos e o próprio $\mathrm{CO}_{2}$ em excesso que, além de alterarem o aroma e sabor natural, provocam a aceleração na senescência dos tecidos vegetais (BRECHT, 1980; KADER, 1986; KADER et al.,

${ }^{1}$ Engenheira de Alimentos - UNICAMP - Mestre em Tecnologia de Alimentos - UFPR.

${ }^{2}$ Professora Adjunta do Departamento de Tecnologia Química da Universidade Federal do Paraná/UFPR - Caixa Postal 19011 - $81.531-990$ - Curitiba, PR. 
1989; ROLLE\& CHISM, 1987; SHEWFELT, 1987;ZAGORY $\&$ KADER, 1988).

A atmosfera ativamente modificada pode ser obtida pela substituição do ar por uma composição gasosa previamente estabelecida, efetuando-se primeiramente o vácuo na embalagem (BALLANTYNE et al., 1988).

O material de embalagem além das funções básicas de proteção, fracionamento e segurança deve apresentar características de permeabilidade que auxiliem na manutenção da atmosfera ativamente modificada, minimizando o desequilíbrio promovido pela respiração do produto. Para tanto a embalagem deve apresentar uma taxa de permeabilidade ao oxigênio $\left(\mathrm{TPO}_{2}\right)$ que compense o seu consumo e uma taxa de permeabilidade ao $\mathrm{CO}_{2}\left(\mathrm{TPCO}_{2}\right)$ que permita a saída do gás que é gerado pela respiração do vegetal (ZAGORY \& KADER, 1988). Entre os filmes plásticos comumente aplicados no acondicionamento de produtos que respiram está o polietileno de baixa densidade que, além do baixo custo e disponibilidade no mercado apresenta boa barreira ao vapor de água, permeabilidade aos gases relativamente alta e resposta favorável a termoselagem. Os laminados como o BOPP/ PEBD (polipropileno biorientado/polietileno de baixa densidade) podem ser utilizados quando se objetiva melhores resultados de impressão e rigidez (BALLANTYNE et al., 1988; KADER et al., 1989; SARANTÓPOULOS et al., 1996).

A análise sensorial tem sido utilizada com sucesso para determinar a qualidade de alface MP. Nessa avaliação, a aparência exerce maior influência no julgamento, pois o escurecimento marron-ferrugem das nervuras e dos tecidos brancos, além de manchas marrom nas folhas e nas extremidades cortadas ou amassadas são os fatores que mais contribuem para a rejeição do produto (KADER et al., 1973; HEIMDAL et al., 1995; SHEWFELT, 1987).

Objetivou-se com este trabalho avaliar a influência dos diferentes filmes das embalagens plásticas utilizadas e da atmosfera modificada na qualidade sensorial da alface nas condições do experimento. Para tanto se monitorou a concentração de $\mathrm{O}_{2}$ e $\mathrm{CO}_{2}$ no interior das embalagens e a qualidade sensorial do produto.

\section{MATERIALEMÉTODOS}

\section{Matéria-prima}

Alfaces (Lactuca sativa L.) crespas da cultivar Verônica, produzidas na região metropolitana de Curitiba, foram adquiridas diretamente do produtor, colhidas pela manhã e transportadas em caixas de madeira com 20 unidades cada.

\section{Embalagem}

Cinco filmes foram testados e comparados entre si:

1. PEBD-50: Polietileno de baixa densidade;

2. PEBD-100: Polietileno de baixa densidade;

3. BOPP- PEBD*: Polietileno biorientado Polietileno de baixa densidade;

4. Conservax: composição não divulgada pelo fornecedor;

5. PEBD-60: Polietileno de baixa densidade.

Os sacos plásticos produzidos com esses filmes: dimensões de 29 × $25 \mathrm{~cm}$.

\section{- Características dos Filmes:}

As determinações das $\mathrm{TPO}_{2}$ foram realizadas por método colorimétrico, segundo procedimento descrito na norma ASTM D 3985-95 e as determinações de $\mathrm{TPCO}_{2}$ por método de aumento da concentração (OLIVEIRA et al., 1996).

A espessura foi determinada com a utilização de um micrômetro de ponta Starret.

\section{Atmosfera modificada}

A simulação da composição do oxigênio e gás carbônico presente no ar ( $21 \%$ de $\mathrm{O}_{2}$ e $0,03 \%$ de $\left.\mathrm{CO}_{2}\right)$ foi obtida por meio da perfuração manual de algumas embalagens constituídas pelo filme PEBD 50, com agulhas de $Æ 0,5 \mathrm{~mm}$, mantendo-se uma distancia de $3 \mathrm{~cm}$ entre cada furo (16 furos a cada $0,81 \mathrm{~m}^{2}$ ), os quais foram denominados de produtos controles. Garantiu-se que com essa perfuração o ar saía e entrava com facilidade através da embalagem sob leve pressão manual.

A composição gasosa ativamente modificada ATM $1\left(5 \%\right.$ de $_{2}$ e $10 \%$ de $\mathrm{CO}_{2}$ ) foi fornecida pela AGA fabricante de gases especiais, em cilindros de $1,5 \mathrm{Kg}$.

\section{Processamento}

As folhas externas com defeitos, danos e necroses foram eliminadas durante a primeira lavagem, em seguida as folhas perfeitas foram destacadas manualmente com faca de aço inoxidável, e fez-se uma segunda seleção e lavagem para eliminar as folhas amassadas, rasgadas ou com escurecimentos das extremidades.

As folhas foram sanitizadas por dez minutos em solução clorada ( $\left.150 \mathrm{mg} \cdot \mathrm{L}^{-1}\right)$, enxagüadas em água potável refrigerada $\left(10^{\circ} \mathrm{C}\right)$, centrifugadas, pesadas $(150 \mathrm{~g} / \mathrm{saco}) \mathrm{e}$ acondicionadas em sacos confeccionados com filmes 
TABELA 1 - Espessura e taxa de permeabilidade ao $\mathrm{O}_{2}\left(\mathrm{TPO}_{2}\right)$ e ao $\mathrm{CO}_{2}\left(\mathrm{TPCO}_{2}\right)$ a $23^{\circ} \mathrm{C}$, a seco e 1 atm de gradiente de pressão parcial de gás permeante.

\begin{tabular}{|c|c|c|c|c|c|c|}
\hline \multirow[t]{2}{*}{ Amostra } & \multicolumn{2}{|c|}{$\begin{array}{l}\text { Espessura } \\
\quad(\mathbf{m m})\end{array}$} & \multicolumn{2}{|c|}{$\begin{array}{c}\mathrm{TPO}_{2} \\
\mathrm{~cm}^{3}\left(\mathrm{CNTP} / \mathrm{m}^{2} / 24 \mathrm{~h}\right)\end{array}$} & \multicolumn{2}{|c|}{$\begin{array}{c}\mathrm{TPCO}_{2} \\
\left.\mathrm{~cm}^{3}(\mathrm{CNTP}) / \mathrm{m}^{2} / 24 \mathrm{~h}\right)\end{array}$} \\
\hline & Média $^{1}$ & $\mathrm{CV}^{4}(\%)$ & Média $^{2}$ & $\mathrm{CV}(\%)$ & Média & $\mathrm{CV}(\%)$ \\
\hline PEBD-50 & 0,05 & 4 & 3.735 & 4 & $12.922^{3^{*}}$ & 27 \\
\hline PEBD-60 & 0,06 & 5 & 2.844 & 5 & $12.073^{3 * *}$ & 11 \\
\hline PEBD-100 & 0,10 & 3 & 1.842 & 4 & $8.825^{3 * *}$ & 12 \\
\hline BOPP/PEBD & 0,067 & 2 & 1.237 & 2 & $4.472^{3^{*}}$ & 7 \\
\hline CONSERVAX & 0,062 & 3 & 845 & 0,3 & $5.977^{3^{*}}$ & 10 \\
\hline
\end{tabular}

${ }^{\mathrm{T}}$ Média: vinte e cinco determinações.

${ }^{2}$ Resultado médio de duas determinações.

${ }^{3 *}$ Resultado médio de três determinações; ${ }^{3 * *}$ resultados médios de quatro determinações.

${ }^{4} \mathrm{CV}$ : coeficiente de variação.

plásticos em unidades de 150 gramas cada um.

A atmosfera foi alterada ativamente por meio de injeção da mistura gasosa após a formação do vácuo e imediatamente antes da selagem das embalagens, operações automaticamente integradas da seladora a vácuo com injeção de gás. A análise do teor de gás realizada imediatamente após a selagem comprovou a substituição total do ar pela mistura gasosa (Figura 01 - tempo zero). Após o fechamento as amostras foram para o refrigerador e mantidas sob por $5-7^{\circ} \mathrm{C}$ durante toda a avaliação (15 dias).

\section{Delineamento experimental}

Os testes foram conduzidos segundo o delineamento experimental inteiramente casualizado, com duas repetições ou blocos. O método de análise dos resultados está descrito no próximo item.

\section{Avaliações}

Foram feitas medidas diárias dos teores de $\mathrm{O}_{2} \mathrm{e} \mathrm{CO}_{2}$ até o terceiro dia e a partir dessa data a cada dois dias, diretamente no interior da embalagem usando o analisador de "headspace" marca ABISS, modelo VAK 12 -MAP03, até que o produto não mais apresentasse condições de consumo. Os valores obtidos em cada leitura foram as médias de dois pacotes.

A avaliação da qualidade sensorial durante o armazenamento foi realizada por meio de uma equipe de oito provadores que apesar de não treinados, eram consumidores de alface fresca e estavam familiarizados com o produto. Receberam orientação sobre a metodologia e sobre as observações pertinentes às alterações mais evidentes, descritas na ficha de análise (Quadro 1). O conteúdo de duas embalagens de cada filme foi apresentado em bandejas para análise da aparência e aroma. Porções menores eram separadas para analise de sabor e textura, oferecidas individualmente para cada provador. O método utilizado foi a Análise Descritiva Qualitativa - ADQ, por meio de escala hedônica de nove pontos para a aparência e defeitos e escala de cinco pontos para sabor, textura e aroma (KADER et al., 1973; MEILGAARD et al., 1991). De acordo com a escala estabelecida (Quadro 1), definiu-se que o limite de aceitação do produto para consumo nos atributos aparência geral e defeitos seria cinco e para os demais atributos dois. Os produtos foram analisados e comparados estatisticamente quanto à qualidade em relação ao tempo de armazenamento. Os dados obtidos foram submetidos à análise de variância (ANOVA) e a comparação das médias pelo teste de Tukey. Não foi realizado análise estatística dos julgamentos entre diferentes embalagens no mesmo período de armazenamento. 
QUADRO 1 - Escala hedônica afetiva numérica.

\begin{tabular}{|c|c|}
\hline Qualidade Geral: & $\begin{array}{l}\text { 9. Excelente, livre de defeitos } \\
\text { 7. Boa, pequenos defeitos } \\
\text { 5. Defeitos médios, não limita para consumo } \\
\text { 3. Pobre, defeitos excessivos, limitada para consumo } \\
\text { 1. Extremamente pobre, não utilizável }\end{array}$ \\
\hline Aroma: & $\begin{array}{l}\text { 1. Nenhum/não típico, odores fortes não característicos } \\
\text { 2. Razoável - início de odores não característicos } \\
\text { 3. Bom } \\
\text { 4. Muito bom, sem alterações } \\
\text { 5. Fresco/excelente }\end{array}$ \\
\hline Sabor: & $\begin{array}{l}\text { 1. Nenhum/não típico } \\
\text { 2. Razoável } \\
\text { 3. Bom } \\
\text { 4. Muito bom } \\
\text { 5. Fresco/excelente }\end{array}$ \\
\hline Textura: & $\begin{array}{l}\text { 1. Pobre/flácida } \\
\text { 2. Razoável } \\
\text { 3. Boa } \\
\text { 4. Muito boa } \\
\text { 5. Excelente/crocante/fresca }\end{array}$ \\
\hline $\begin{array}{l}\text { Defeitos: } \\
\text { - E.E.F.: escurecimento devido } \\
\text { à necroses pontuais no meio da } \\
\text { folha ou na extremidade } \\
\text { - E.E.H.: escurecimento da } \\
\text { haste "róseo-ferrugem a marrom" }\end{array}$ & $\begin{array}{l}\text { 9. Nenhum } \\
\text { 7. Leve } \\
\text { 5. Moderado } \\
\text { 3. Severo } \\
\text { 1. Extremo }\end{array}$ \\
\hline
\end{tabular}

\section{RESULTADOS E DISCUSSÃO}

A variação da composição gasosa no interior das embalagens pode ser observada nas Figuras 1 e 2, para $\mathrm{O}_{2}$ e $\mathrm{CO}_{2, .}$ respectivamente.

Em todas as embalagens ocorreu uma redução no teor de oxigênio nas primeiras 48 horas. A partir do segundo dia de armazenamento observou-se menor queda, o que indicou que a velocidade de respiração diminuiu significativamente. A respiração mais acelerada nas primeiras horas pode ter sido devido ao metabolismo mais acelerado da planta logo após a colheita, o que poderia ter sido minimizado por uma etapa prévia de pré-resfriamento (CHITARRA \& CHITARRA, 1990). Além disso, o resfriamento (refrigerador convencional) propicia um longo tempo até que a temperatura de refrigeração final seja alcançada. Esse efeito pode ser minimizado em condições de processamento totalmente climatizadas, ou seja, o produto é manipulado em temperaturas baixas e acondicionado já nessa condição, o que seria o ideal para produtos minimamente processados (WILLEY, 1997).

Nas embalagens do filme PEBD-50, após as primeiras 48 horas de armazenamento quando o nível de $\mathrm{O}_{2}$ atingiu menos de $1,5 \%$, iniciou-se o processo inverso, ou seja, o aumento gradual desse gás na embalagem indicou que a permeação do $\mathrm{O}_{2}$ através do filme foi maior do que o seu consumo pela respiração do produto. Apesar disso, o valor máximo de $\mathrm{O}_{2}$ não foi superior a $5 \%$ mesmo após quinze dias de armazenamento, um pouco superior ao recomendado por Hamza et al. (1996) para alface romana refrigerada minimamente processada, quando os autores citam que a concentração gasosa ideal é de 1 a $3 \%$ de $\mathrm{O}_{2} \mathrm{e}$ de no máximo $10 \%$ de $\mathrm{CO}_{2}$ para que a taxa de respiração sofra um decréscimo significativo sem efeitos negativos para a qualidade. Ao contrario do oxigênio, o nível de $\mathrm{CO}_{2}$ não se manteve próximo aos $10 \%$ inicialmente promovidos pela ATM 1. Observou-se a redução gradual do $\mathrm{CO}_{2}$ até $3 \%$ em sete dias, permanecendo desse ponto em diante nessa concentração.

Nas embalagens compostas pelo filmes PEBD-60, a concentração de oxigênio se manteve entre 1,3 e 2,3\% durante todo o período avaliado. Pode-se considerar que houve uma estabilização da concentração do oxigênio após as primeiras horas de estocagem o que indicou que, nesse 

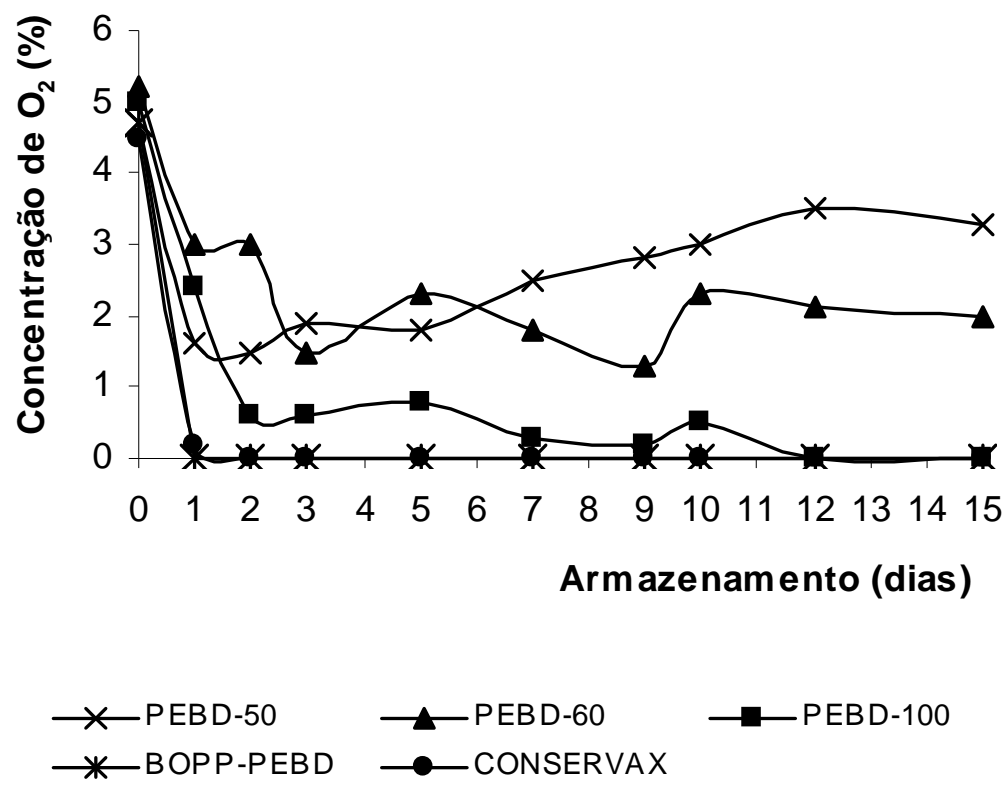

FIGURA 1 - Variação do oxigênio no interior das embalagens.

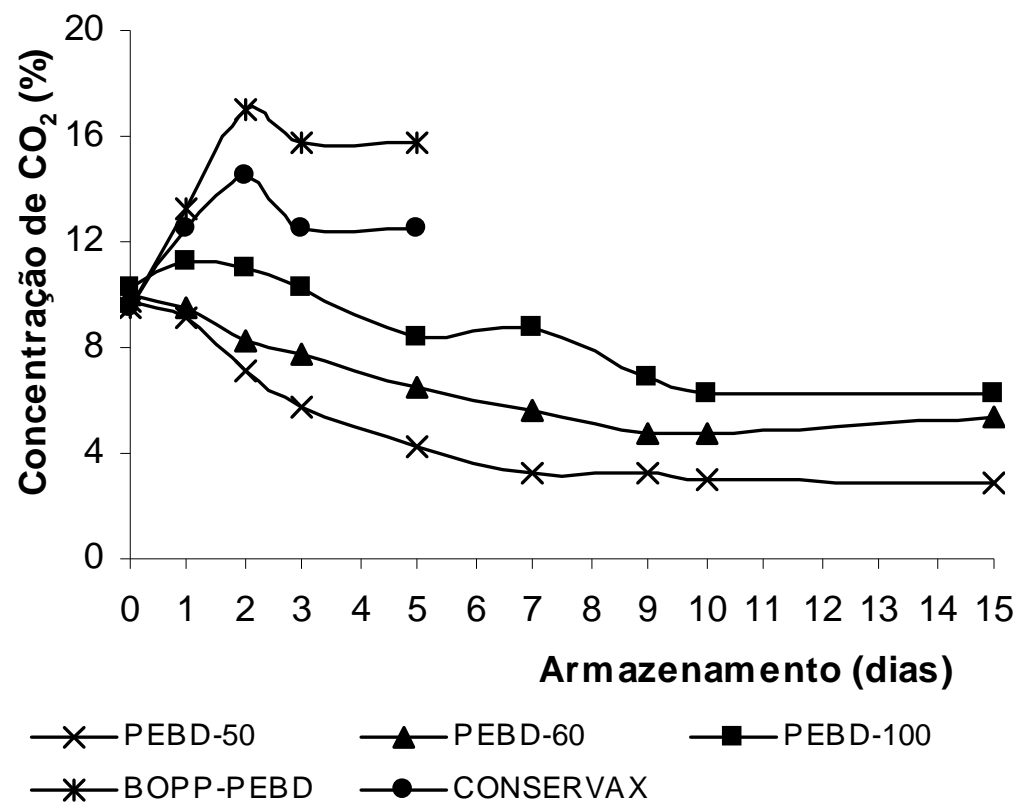

FIGURA 2 - Variação do gás carbônico no interior das embalagens. 
período, a permeação do $\mathrm{O}_{2}$ através do filme nas condições do experimento foi adequada para suprimir o seu consumo devido à respiração da alface. Quanto à concentração de $\mathrm{CO}_{2}$, a redução do gás durante o armazenamento também foi evidente, sendo que após sete dias a concentração do gás carbônico estava em $5,6 \%$ e se manteve próximo a esse nível até o final das avaliações.

No filme PEBD-100 observa-se que após as 48 horas iniciais a concentração do oxigênio atingiu valores menores que $1 \%$ e decresceu lentamente até zerar aos doze dias de armazenamento. A permeação do $\mathrm{O}_{2}$ nesse filme foi insuficiente para manter o nível de $\mathrm{O}_{2}$ acima de zero por todo o período avaliado. $\mathrm{O}$ efeito positivo nessa embalagem foi à manutenção dos níveis de $\mathrm{CO}_{2}$ em no mínimo 6\% até o final do armazenamento. As embalagens com os filmes BOPP-PEBD e Conservax não apresentaram permeação de $\mathrm{O}_{2}$ e $\mathrm{CO}_{2}$ suficientes para acompanhar a respiração do vegetal. O oxigênio introduzido no interior da embalagem foi rapidamente metabolizado nas primeiras 24 horas e o $\mathrm{CO}_{2}$ aumentou significativamente (Figura 2). Dois dias após os produtos estarem nessas condições, a análise sensorial detectou alterações no aroma $(p=0,05)$ e no quinto dia de armazenamento houve rejeição total e descarte dos mesmos devido à degradação do produto e formação de odor etanólico, característico de processo fermentativo. (Tabela 2).

TABELA 2 - Análise sensorial da alface crespa MP armazenada em filmes flexíveis a $5^{\circ} \mathrm{C}$.

\begin{tabular}{|c|c|c|c|c|c|c|c|}
\hline Parâmetro & Dia & $\begin{array}{c}\text { Filme } \\
\text { Perfurado }\end{array}$ & $\begin{array}{c}\text { Filme } \\
\text { Pebd50 }\end{array}$ & Filme PEBD60 & $\begin{array}{c}\text { Filme PEBD } \\
100\end{array}$ & $\begin{array}{c}\text { Filme } \\
\text { BOPP-PE }\end{array}$ & $\begin{array}{c}\text { Filme } \\
\text { Conservax }\end{array}$ \\
\hline \multirow[t]{5}{*}{ Aparência } & 01 & $7,40^{\mathrm{a}}$ & $6,75^{\mathrm{a}}$ & $7,90^{\mathrm{a}}$ & $7,40^{\mathrm{ab}}$ & $7,90^{\mathrm{a}}$ & $7,85^{\mathrm{a}}$ \\
\hline & 03 & n.a. & n.a. & n.a. & n.a. & $7,00^{\mathrm{a}}$ & $6,00^{b}$ \\
\hline & 05 & $6,30^{b}$ & $6,00^{\mathrm{ab}}$ & $6,30^{b}$ & $7,50^{\mathrm{a}}$ & $1,00^{\mathrm{b}}$ & $1,00^{\mathrm{c}}$ \\
\hline & 10 & $3,60^{c}$ & $5,00^{\mathrm{bc}}$ & $5,25^{\mathrm{bc}}$ & $6,40^{\mathrm{b}}$ & i.c. & i.c.- \\
\hline & 15 & $2,90^{\mathrm{c}}$ & $3,70^{\mathrm{c}}$ & $4,75^{\mathrm{c}}$ & $3,75^{\mathrm{c}}$ & i.c. & i.c.- \\
\hline \multirow[t]{5}{*}{ Aroma } & 01 & $4,10^{\mathrm{a}}$ & $4,70^{\mathrm{a}}$ & $4,50^{\mathrm{a}}$ & $3,90^{\mathrm{ab}}$ & $4,25^{\mathrm{a}}$ & $4,25^{\mathrm{a}}$ \\
\hline & 03 & n.a. & n.a. & n.a. & n.a. & $1,40^{\mathrm{b}}$ & $2,10^{b}$ \\
\hline & 05 & $3,80^{\mathrm{a}}$ & $3,75^{\mathrm{b}}$ & $4,30^{\mathrm{a}}$ & $4,10^{\mathrm{a}}$ & $1,00^{\mathrm{b}}$ & $1,00^{\mathrm{c}}$ \\
\hline & 10 & $2,90^{\mathrm{b}}$ & $2,60^{c}$ & $2,25^{\mathrm{b}}$ & $3,00^{\mathrm{bc}}$ & i.c. & i.c.- \\
\hline & 15 & $1,80^{\mathrm{c}}$ & $2,90^{\mathrm{c}}$ & $2,50^{b}$ & $2,10^{c}$ & i.c. & i.c.- \\
\hline \multirow[t]{5}{*}{ Sabor } & 01 & $3,70^{\mathrm{a}}$ & $4,20^{\mathrm{a}}$ & $4,30^{\mathrm{a}}$ & $4,00^{\mathrm{a}}$ & $4,40^{\mathrm{a}}$ & $4,40^{\mathrm{a}}$ \\
\hline & 03 & n.a. & n.a. & n.a. & n.a. & $3,00^{b}$ & $2,40^{\mathrm{b}}$ \\
\hline & 05 & $3,70^{\mathrm{a}}$ & $3,90^{\mathrm{ab}}$ & $3,70^{\mathrm{ab}}$ & $3,75^{\mathrm{a}}$ & $1,00^{\mathrm{c}}$ & $1,00^{\mathrm{c}}$ \\
\hline & 10 & $2,90^{\mathrm{b}}$ & $3,20^{b c}$ & $3,25^{\mathrm{b}}$ & $3,50^{\mathrm{a}}$ & i.c. & i.c.- \\
\hline & 15 & $1,50^{\mathrm{c}}$ & $2,70^{c}$ & $2,75^{\mathrm{b}}$ & $1,40^{\mathrm{b}}$ & i.c. & i.c.- \\
\hline \multirow[t]{5}{*}{ Textura } & 01 & $4,40^{\mathrm{a}}$ & $4,30^{\mathrm{a}}$ & $4,60^{\mathrm{a}}$ & $3,90^{\mathrm{a}}$ & $4,40^{\mathrm{a}}$ & $4,40^{\mathrm{a}}$ \\
\hline & 03 & n.a. & n.a. & n.a. & n.a. & $3,70^{b}$ & $3,40^{\mathrm{b}}$ \\
\hline & 05 & $3,90^{\mathrm{ab}}$ & $-3,60^{b}$ & $4,00^{\mathrm{a}}$ & $3,60^{\mathrm{ab}}$ & $1,00^{c}$ & $1,00^{\mathrm{c}}$ \\
\hline & 10 & $3,30^{b}$ & $2,90^{b c}$ & $3,75^{\mathrm{ab}}$ & $2,60^{b c}$ & i.c. & i.c.- \\
\hline & 15 & $2,70^{c}$ & $2,50^{c}$ & $2,50^{b}$ & $2,40^{c}$ & i.c. & i.c.- \\
\hline
\end{tabular}

a,b,c - médias da mesma coluna com letras iguais não diferem significativamente ao nível de $5 \%$.

n.a. - não analisado.

i.c. - impróprio para consumo. 
Na análise sensorial (Tabela 2 e Figura 3), a aparência dos produtos foi influenciada principalmente pela presença de escurecimento de coloração rósea-ferrugem nas nervuras centrais e pelo escurecimento das folhas quando levemente cortadas ou amassadas, defeitos provocados geralmente por enzimas, citados em Mateos et al. (1993) ao submeterem a alface inteira ou minimamente processada a $10 \%$ de $\mathrm{CO}_{2}$ evitando o escurecimento.

A alface embalada em PEBD-100 se manteve com boa aparência nos primeiros cinco dias, sem sinais de escurecimento das folhas e nervuras. Observa-se que nesse período, a concentração de $\mathrm{CO}_{2}$ das embalagens de PEBD100 esteve superior a $8,5 \%$, o que pode ter sido decisivo na prevenção de escurecimento de nervuras e folhas da alface, devido ao efeito anti-enzimático desse gás. Segundo Hamza et al. (1996) e Mateos et al. (1993), o efeito do incremento de $\mathrm{CO}_{2}$ está relacionado com a redução da atividade enzimática, em especial da polifenoloxidase. Esse efeito foi parcial nas alfaces dos filmes PEBD-50 e 60, nas quais a concentração de $\mathrm{CO}_{2}$ nesse mesmo período era 4,2 e 6,5\%, respectivamente. A alface, nessas duas embalagens, perdeu gradualmente a qualidade desde a primeira avaliação devido principalmente ao escurecimento das nervuras das folhas. As diferenças entre as médias foram significativas $(\mathrm{p}=0,05)$ entre a primeira e a segunda avaliação sensorial (cinco dias) e entre a segunda e quarta (de cinco a quinze dias), sendo que nessa ultima análise as médias foram inferiores ao limite estabelecido como aceitável (cinco pontos).

Nas embalagens de PEBD-100, o benefício da maior concentração de $\mathrm{CO}_{2}$ foi contraposto pelo efeito negativo da baixa concentração do $\mathrm{O}_{2}$ a partir do quinto dia de armazenamento, resultando em alterações sensoriais significativas a partir do quinto de armazenamento. $\mathrm{Na}$ última análise, a alface embalada em PEBD-100 apresentou qualidade inferior às demais devido à incidência de escurecimento das folhas, alterações no aroma e no sabor. Hamza et al. (1996) e Mateos et al. (1993) citam que para a alface crespa minimamente processada deve-se observar limites mínimos de pelo menos $1 \%$ de $\mathrm{O}_{2}$. No caso da cultivar Verônica os efeitos negativos na qualidade sensorial foram pronunciados em níveis menores que $0,6 \%$ (diferença significativa no aroma entre as médias do quinto e décimo dia de avaliação e na aparência entre as medias do décimo e décimo quinto dia de avaliação, abaixo dos limites estabelecidos para aceitação para PEBD-100).

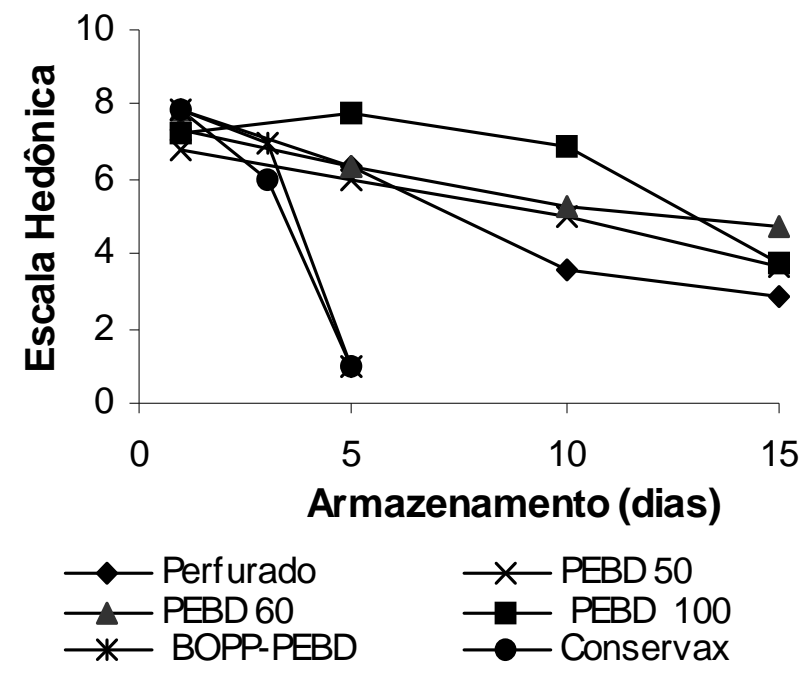

FIGURA 3 - Análise sensorial da aparência da alface.

Ciênc. agrotec., Lavras, v. 29, n. 4, p. 824-832, jul./ago., 2005 
As alfaces embaladas em PEBD-50 e 60 apresentaram comportamento semelhante até o final do experimento. Entretanto, embora as médias dos dois produtos não tenham sido comparadas estatisticamente, existe uma diferença entre os valores absolutos no décimo quinto dia de avaliação, sendo a aparência da alface em PEBD-60 melhor avaliada do que aquela em PEBD-50. O filme PEBD-60 possui características intermediárias de permeabilidade ao $\mathrm{O}_{2}$ e $\mathrm{CO}_{2}$ em relação aos filmes PEBD-50 e 100 (Tabela 01), o que permitiu maior retenção do $\mathrm{CO}_{2} \mathrm{em}$ comparação com o filme PEBD-50 e a manutenção da concentração de $\mathrm{O}_{2}$ ao redor do produto entre $1 \%$ e $3 \%$ durante os 15 dias de armazenamento, o que pode explicar a diferença observada entre as médias absolutas entre os produtos nessas embalagens.

A alface embalada sem atmosfera modificada (filme perfurado) perdeu qualidade gradualmente entre o quinto e o décimo dia, sendo então, rejeitada no atributo aparência.

No atributo textura não houve diferença significativa nos produtos embalados em diferentes filmes.

A variação da espessura dos filmes de PEBD implica na variação da $\mathrm{TPCO}_{2}$ e da $\mathrm{TPO}_{2}$ ao mesmo tempo e nas mesmas proporções, o que torna difícil a adequação das taxas de permeabilidade à variação de gases devido ao processo de respiração apenas pela alteração dessa variável. Mesmo com essa deficiência, as alfaces embaladas nos filmes PEBD, em atmosfera modificada foram superiores ao produto controle durante toda a avaliação, principalmente quanto à aparência.

\section{CONCLUSÃO}

A qualidade da alface MP é diretamente dependente do tipo de embalagem utilizada. Dentre os filmes avaliados nesse trabalho, o PEBD 60 foi o que melhor correspondeu à adequação entre a variação de gases do metabolismo e a permeação desses mesmos gases $\left(\mathrm{O}_{2}\right.$ e $\left.\mathrm{CO}_{2}\right)$ através da embalagem, seguidos de perto pelo filme PEBD 50, nas condições do experimento. Porém, em todos os filmes testados houve alteração na atmosfera inicialmente modificada. Os filmes de menor permeabilidade promoveram a deterioração do produto.

A manutenção da atmosfera modificada ao redor do produto $0,6 \%$ a $3 \%$ de $\mathrm{O}_{2}$ e $8,5 \%$ a $10 \%$ de $\mathrm{CO}_{2}$ foram determinantes na extensão do tempo de conservação da alface crespa cultivar Verônica minimamente processada, porém, nenhum dos filmes testados promoveu esse equilíbrio durante os quinze dias de armazenamento.

A avaliação sensorial confirma o melhor desempenho dos filmes PEBD 60 e 50 e na manutenção da qualidade, sendo que a aparência da alface foi decisiva na determinação da aceitação do produto. Entretanto, todos os produtos embalados nos filmes de PEBD (60, 50 e 100) apresentaram aparência superior ao produto sem atmosfera modificada durante todo o período de armazenamento. Assim, concluímos que, levando-se em conta os aspectos sensoriais, a modificação ativa da atmosfera na alface testada é decisiva para aumentar sua vida útil.

\section{AGRADECIMENTOS}

Ao CETEA - ITAL, pelas análises de caracterização de permeabilidade e espessura dos filmes.

À Aga-S.A., pelo fornecimento dos gases e pelo equipamento para determinação das concentrações gasosas.

Aos fornecedores das embalagens: PROBAG, ITAP eENVASE.

\section{REFERÊNCIAS BIBLIOGRÁFICAS}

BALLANTYNE, A.; STARK, R.; SELMAN, J. D. Modified atmosphere packaging of shredded lettuce. International Journal of Food Science and Technology, Oxford, v. 23, p. 267-274, 1988.

CHITARRA, M. I. F. Processamento mínimo de vegetais: filme técnico. Viçosa: Centro de Produções Técnicas, 1998.

CHITARRA, M. I. F.; CHITARRA, A. B. Pós-colheita de frutos e hortaliças: fisiologia e manuseio. Lavras: ESAL/ FAEPE, 1990.

BRECHT, E. P. Use of controlled atmospheres to retard deterioration of produce. Food Technology, Chicago, v. 34, n. 3, p. 45-50, 1980.

HAMZA, F. et al. Storage of minimally processed romaine lettuce under controlled atmosphere. Journal of Food Quality, Connecticut, v. 19, p. 177-188, 1996.

HEIMDAL, H. et al. Biochemical changes and sensorial quality of shredded and MA-packaged iceberg lettuce. Journal of Food Science, Chicago, v. 60, n. 6, p. 1265-1276, 1995.

KADER, A. A. Biochemical and physiological basis for effects of controlled and modified atmospheres on fruits and vegetables. Food Technology, Chicago, v. 40, n. 5, p. 99-104, 1986. 
KADER, A. A.; LIPTON, J. W.; MORRIS, L. L. System for scoring quality of harvest lettuce. HortScience, California, v. 8, n. 5, p. 408-409, 1973.

KADER, A. A.; ZAGORY, D.; KERBEL, E. L. Modified atmospheres packaging of fruits and vegetables. Critical Reviews in Food Science and Nutrition, Chicago, v. 28, n. 1, p. 1-30, 1989.

MATEOS et al. Phenolic metabolism and fermentation of intact and cut lettuce exposed to $\mathrm{CO}_{2}$ - enriched atmospheres. Postharvest Biology and Technology, Chicago, v. 3, p. 225-233, 1993.

MEILGAARD, M.; CIVILLE, V. G.; CARR, B. T. Sensory evaluation techniques. 2. ed. Boston: CRP, 1991.

NASCIMENTO, E. F.; MOLICA, E. M.; MORAES, J. S. Hortaliças minimamente processadas: mercado e produção. Brasília: EMATER, 2000.

OLIVEIRA, L. M. et al. Ensaios para avaliação de embalagens plásticas flexíveis. Campinas: CETEA/ITAL, 1996.219p.
PINHEIRO, F. Longe do fogão. Supermix, São Paulo, n. 61, p. 8-15, set. 2000.

ROLLE, R. S.; CHISM, G. W. Physiological consequences of minimally processed fruits and vegetables. Journal of Food Quality, Connecticut, v. 10, p. 157-177, 1987.

SARANTÓPOULOS, C. I. G. L. et al. Embalagens com atmosfera modificada. Campinas: ITAL-CETEA, 1996.

SHELFT, R. Postharvest treatment for extending the shelf life of fruits and vegetables. Food Technology, Chicago, v. 40, n. 5, p. 70-85, 1986.

SHEWFELT, R. Quality of minimally processed fruits and vegetables. Journal of Food Quality, Connecticut, v. 10, p. 143-156, 1987.

WILLEY, R. Frutas y hortalizas mínimamente procesadas y refrigeradas. Tradução de José Fernández-Salguero Carretero. Zaragoza: Acribia, 1997.

ZAGORY, D.; KADER, A. A. Modified atmosphere packaging of fresh products. Food Technology, Chicago, v. 42, n. 9, p. 70-77, 1988. 